Check for updates

Cite this: RSC Adv., 2017, 7, 38001

Received 19th June 2017

Accepted 27th July 2017

DOI: $10.1039 / c 7 r a 06844 a$

rsc.li/rsc-advances

\section{Enhanced cellular uptake of iron oxide nanoparticles modified with 1,2- dimyristoyl-sn-glycero-3-phosphocholine}

\begin{abstract}
Lichao Su, (D) a Baolin Zhang, (D) *a Yinping Huang, ${ }^{\text {a }}$ Ziliang Fan ${ }^{b}$ and Yingzheng Zhao*b
It is important for nanoparticles to enter cells to implement their biological applications. We synthesized and characterized superparamagnetic iron oxide nanoparticles (SPIONs) modified with poly(ethylene glycol) (PEG) and polyethyleneimine (PEI) (PEG/PEI-SPIONs), and further with 1,2-dimyristoyl-sn-glycero-3phosphocholine (DMPC) (DMPC-SPIONs) to improve their intracellular uptake. The nanoparticles internalized into PC-12 cells were observed by transmission electron microscopy (TEM) and quantified by inductively coupled plasma emission spectroscopy (ICP-OES). There was a much greater uptake of DMPC-SPIONs than PEG/PEI-SPIONs into PC-12 cells and remarkable amounts of accumulated nanoparticles were found in the lysosome, endoplasmic reticulum, mitochondria, vesicles, and around the nucleus, and some nanoparticles remained on the cell membrane. This can be attributed to the similarity between the chemical structures of DMPC and membrane phospholipids which result in the fusion of DMPC and cell membranes. Our results encourage further research on DMPC-SPIONs as drug carriers, transfection agents, MRI contrast agents for cells and hyperthermia agents.
\end{abstract}

\section{Introduction}

The cell membrane separates the interior of cells from the outside environment. The entrance of nanomaterials into cell membranes is inevitable for applications in drug delivery, magnetic hyperthermia, transfection and MRI imaging of cells. $^{1-4}$ The interaction between nanoparticles and cell membranes is impacted by the surface modification, charge, size and shape of the nanoparticles. ${ }^{5-7}$ Phospholipids are important components of mammalian cell membranes. ${ }^{8}$ As a typical phospholipid, 1,2-dimyristoyl-sn-glycero-3-phosphocholine (DMPC) has a long double carbon chain with the zwitterion head groups containing phosphate and choline. DMPCs are endogenous molecules and are completely biodegradable. ${ }^{9,10}$ The fusion of DMPC and cell membranes is able to enhance the interaction between the DMPC modified nanoparticles and cells, due to the phospholipid enhanced permeability and retention (EPR) effect. ${ }^{11-14}$ Phospholipids merged with the cell membrane, lipid exchange occurred and the gold nanoparticles modified with phospholipid could integrate within the membrane; phospholipids favor fusogenesis with the membrane of living cells. ${ }^{15-17}$ Strong interaction between

\footnotetext{
${ }^{a}$ State Key Laboratory Breeding Base of Nonferrous Metals and Specific Materials Processing, School of Materials Science and Engineering, Guilin University of Technology, Jian Gan Road 12, Guilin, Guangxi, 541004, China. E-mail: baolinzhang@ymail.com; zhangbaolin@glut.edu.cn

${ }^{b}$ College of Pharmaceutical Sciences, Wenzhou Medical University, Wenzhou, Zhejiang, 325035, China. E-mail: pharmtds@163.com
}

poly(ethylene glycol) (PEG) stabilized positive liposomes and HeLa cells were found. ${ }^{16}$ Quantum dot-conjugated lipids were attached to cell membranes. ${ }^{17}$ However, the modification processes of phospholipids on nanoparticles in these works are relatively complex, and direct observation by transmission electron microscopy (TEM) of the distribution of nanoparticles in cellular organelles is absent. In the present work, PEG/PEISPIONs were prepared by the polyol method. ${ }^{18,19}$ PEG increases the colloidal stability of the nanoparticles in the high ionic strength cellular medium, and makes the nanoparticles biocompatible by reducing their cytotoxicity, and PEG is resistant against protein adsorption. ${ }^{15}$ Positive polyethyleneimine (PEI) is tending to be attracted to the negative membranes of cells and PEI provides conjugation with other functional molecules such DMPC. DMPC modified superparamagnetic iron oxide nanoparticles (DMPC-SPIONs) were very easily synthesized in this work. The uptake and distribution of DMPCSPIONs in the PC-12 cells were investigated and compared with those of PEG/PEI-SPIONs. We have observed remarkable uptake of DMPC-SPIONs into the cells, this can make DMPC-SPIONs potential drug carriers, transfection agents, MRI contrast agents for cells and hyperthermia agents.

\section{Experimental}

\subsection{Synthesis of DMPC-SPIONs}

The raw materials used and the synthesis of PEG/PEI-SPIONS were reported in our previous published work. ${ }^{18,19}$ DMPCSPIONs were prepared by mixing $20 \mathrm{mg}$ of DMPC with $20 \mathrm{~mL}$ 
of $1 \mathrm{mg} \mathrm{mL} \mathrm{mL}^{-1}$ PEG/PEI-SPIONs dispersed in deionized water. After being shaken together at $4{ }^{\circ} \mathrm{C}$ for $5 \mathrm{~h}$, and resting at $4{ }^{\circ} \mathrm{C}$ in refrigerator overnight, the mixture was dialyzed against deionized water for $120 \mathrm{~h}$ (MWCO 100000 dialysis bag, Spectrum Labs, USA).

\subsection{Characterization of the SPIONs}

The morphology of the as-synthesized nanoparticles was observed under transmission electron microscopy (TEM, JEM2100F). The zeta potential and hydrodynamic diameters of the nanoparticles were measured by a Zetasizer Nano ZS90 (Malvern Instruments). Fourier transform infrared spectroscopy (FTIR, Nicolet Nexus 470) and thermogravimetric analyses (TGA, TA Instruments Q500) were used to ascertain the DMPC on the SPIONs. The X-ray photoelectron spectroscopy (XPS) of the dried sample was performed in vacuum on Thermo ESCALAB 250 to further characterize the coating materials. For XPS analysis, particle dispersions were dropped on a silicon wafer and the solvent was air dried. The spectra were measured using a monochromatic $\mathrm{Al} \mathrm{K} \alpha$ source $(h \nu=1486.6 \mathrm{eV})$ at $45^{\circ}$ takeoff angle and pass energies of $20 \mathrm{eV}$ and $100 \mathrm{eV}$ for the high resolution and survey spectra, respectively. Calibration of the binding energy (BE) of the measured spectra was performed at the $\mathrm{C} 1 \mathrm{~s}$ peak of the hydrocarbons $(\mathrm{BE}=285 \mathrm{eV})$ in the coating layer as the internal reference. The saturation magnetizations of PEG/PEI-SPIONs and DMPC-SPIONs were determined by the superconducting quantum interference device (SQUID, MPMS XL-7, Quantum Design, USA).

\subsection{Cytotoxicity assay in vitro}

The PC-12 cell line derived from the transplantable pheochromocytoma of the rat adrenal medulla was purchased from the Institute of Biochemistry and Cell Biology (Shanghai, China). In vitro cell viability of PC-12 cells exposed to the SPIONs was assessed by using an MTT cytotoxicity assay. MTT assay was used to evaluate cytotoxicities of nanoparticles against PC-12 cells. The cells were seeded in 96-well plates at $1 \times 10^{5}$ cells per well in $200 \mu \mathrm{L}$ of complete DMEM and incubated at $37^{\circ} \mathrm{C}$ in $5 \% \mathrm{CO}_{2}$ atmosphere for $24 \mathrm{~h}$. After removing the culture medium, different concentrations $\left(0-200 \mu \mathrm{g} \mathrm{mL}{ }^{-1}\right)$ of PEG/PEISPIONs or DMPC-SPIONs in complete DMEM were added. Cell viabilities after incubation with DMPC-SPIONs or PEG/PEISPIONs for $24 \mathrm{~h}$ were evaluated by MTT assay.

\subsection{PC-12 cells cultured with the nanoparticles and the preparation of TEM samples}

PC-12 cells were seeded onto 6-well culture plates at a density of $1 \times 10^{5}$ per well and cultured in complete DMEM for $24 \mathrm{~h}$. The isolated cells were incubated for $12 \mathrm{~h}$ with fresh complete DMEM containing PEG/PEI-SPIONs $\left(200 \mu \mathrm{g} \mathrm{mL}{ }^{-1} \mathrm{Fe}\right)$ or DMPCSPIONs $\left(200 \mu \mathrm{g} \mathrm{mL}^{-1} \mathrm{Fe}\right)$. The PC-12 cells collected were fixed with $2.5 \%$ glutaraldehyde and $0.1 \mathrm{M}$ sodium cacodylate for $1 \mathrm{~h}$. The samples were then rinsed with sodium cacodylate, fixed again with $1 \%$ osmium tetroxide for $1 \mathrm{~h}$. After dehydrated by rinsing with $50 \%, 70 \%, 95 \%$, and $100 \%$ ethanol, the samples were impregnated in a $1: 1$ mixture of acetone and Epon 812 at room temperature for one night. Then the samples were embedded in Epon 812 resin at $60{ }^{\circ} \mathrm{C}$. The embedded samples were cut into ultra-thin section with a PT-XL ultramicrotome (RMC, Boeckeler Instruments, USA) using the glass knife. Sections were then transferred to a copper grid coated with a carbon film. The samples were lightly stained with $0.5 \%$ uranyl acetate and lead citrate solution then subjected to the TEM examination (JEM-2100F and H-7650).

\subsection{Preparation of the samples for ICP-OES}

The iron content of PC-12 cells incubated with DMPC-SPIONs or PEG/PEI-SPIONs was assessed by inductively coupled plasmaoptical emission spectroscopy (ICP-OES, Optima 8000). The cells growing on 6-well culture plates were washed twice with 5 $\mathrm{mL}$ of PBS (0.01 M, pH 7.4) to eliminate the iron oxide in the solution. After completely removing the PBS, the cells were frozen and the dishes were stored at $-4{ }^{\circ} \mathrm{C}$. Cells were pulverized by the ultrasonic cell breaker, $1 \mathrm{~mL}$ of concentrated nitric acid and $0.2 \mathrm{~mL}$ of concentrated hydrochloric acid were added to the sample in a tube and heated at $80{ }^{\circ} \mathrm{C}$ for $2 \mathrm{~h}$, then $0.1 \mathrm{~mL}$ of Triton X-100 (Sinopharm Chemical Reagent, China) was added to the tube for $1 \mathrm{~h}$. After digestion, the solution was diluted to $10 \mathrm{~mL}$ for ICP-OES tests.

\section{Results and discussion}

\subsection{Characterization of the nanoparticles}

The TEM morphologies and size distributions of as-synthesized DMPC-SPIONs and PEG/PEI-SPIONs are shown in Fig. 1, these nanoparticles are well dispersed with average sizes of $15.3 \pm$ $2.2 \mathrm{~nm}$ and $14.8 \pm 1.9 \mathrm{~nm}$, respectively. The XRD patterns of DMPC-SPIONs and PEG/PEI-SPIONs are shown in Fig. 2. The peaks at $30.09^{\circ}, 35.44^{\circ}, 43.07^{\circ}, 53.43^{\circ}, 56.96^{\circ}, 62.55^{\circ}$ and $74.00^{\circ}$ match the crystal planes (220), (311), (400), (422), (511), (440) and (533) of magnetite $\left(\mathrm{Fe}_{3} \mathrm{O}_{4}\right)$ crystal (JCPDS: 01-085-1436), respectively. The spinel crystal structure of magnetite is very similar to that of maghemite $\left(\gamma-\mathrm{Fe}_{2} \mathrm{O}_{3}\right)$, and SPIONs are often a mixture of magnetite and maghemite. ${ }^{18,22}$ The hydrodynamic sizes of PEG/PEI-SPIONs and DMPC-SPIONs are 24 and $31 \mathrm{~nm}$, and their zeta potential values are 15.4 and $12.5 \mathrm{mV}$, respectively (Table 1).

Fig. 3 shows the FTIR spectra of DMPC-SPIONs and PEG/PEISPIONs. The characteristic peaks around $970 \mathrm{~cm}^{-1}$ can be assigned to the $\mathrm{CN}^{+}-\left(\mathrm{CH}_{3}\right)_{3}$ asymmetric vibrations of DMPC, ${ }^{19}$ which cannot be found in PEG/PEI-SPIONs. The absorption peaks at about $1235 \mathrm{~cm}^{-1}$ represent the vibrational modes of $\mathrm{PO}_{2}{ }^{-}$head groups, carbonyl $(\mathrm{C}=\mathrm{O})$ vibrations are around 1740 $\mathrm{cm}^{-1} \cdot{ }^{20,21}$ To further characterize the surface modification of the DMPC-SPIONs, the X-ray photoelectron spectroscopy (XPS, ESCALAB 250Xi) measurement was carried out. The survey XPS spectrum of the DMPC-SPIONs is shown in Fig. 4a, and the peaks at $711 \mathrm{eV}, 530 \mathrm{eV}, 400 \mathrm{eV}, 286 \mathrm{eV}$ and $134.1 \mathrm{eV}$ correspond to the Fe 2p, O 1s, N 1s, C 1s and P 2p, respectively. Fig. $4 \mathrm{~b}$ shows the Fe $2 p$ spectrum corresponding to Fe $2 \mathrm{p}_{3 / 2}(711.7 \mathrm{eV})$ and $\mathrm{Fe} 2 \mathrm{p}_{1 / 2}(725.6 \mathrm{eV})$ peaks. ${ }^{22}$ As shown in Fig. $4 \mathrm{c}$, the binding energy at $134.1 \mathrm{eV}$ belongs to $\mathrm{P} 2 \mathrm{p}$ of DMPC-SPIONs, ${ }^{23,24}$ the $\mathrm{N} 1 \mathrm{~s}$ 

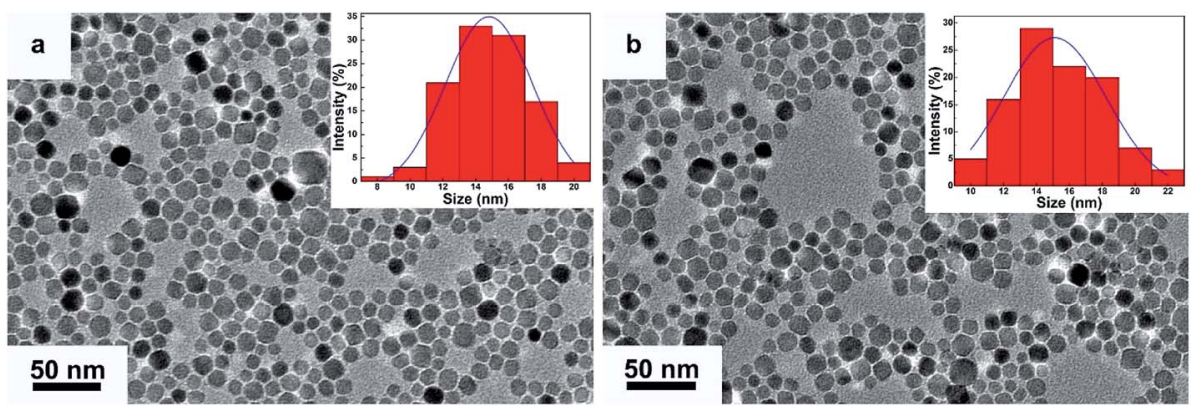

Fig. 1 TEM images and size distributions of DMPC-SPIONs (a) and PEG/PEI-SPIONs (b).

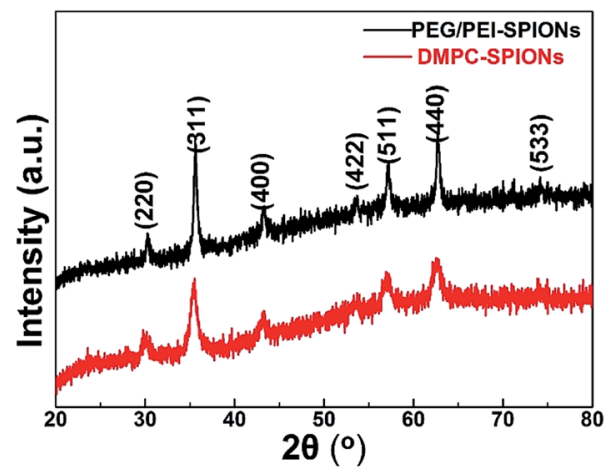

Fig. 2 XRD spectra of DMPC-SPIONs and PEG/PEI-SPIONs.

Table 1 Hydrodynamic sizes, zeta potential of PEG/PEI-SPIONs and DMPC-SPIONs

\begin{tabular}{lll}
\hline & PEG/PEI-SPIONs & DMPC-SPIONs \\
\hline Size $(\mathrm{nm})$ & 24.0 & 31.0 \\
Zeta potential $(\mathrm{mV})$ & 15.4 & 12.5
\end{tabular}

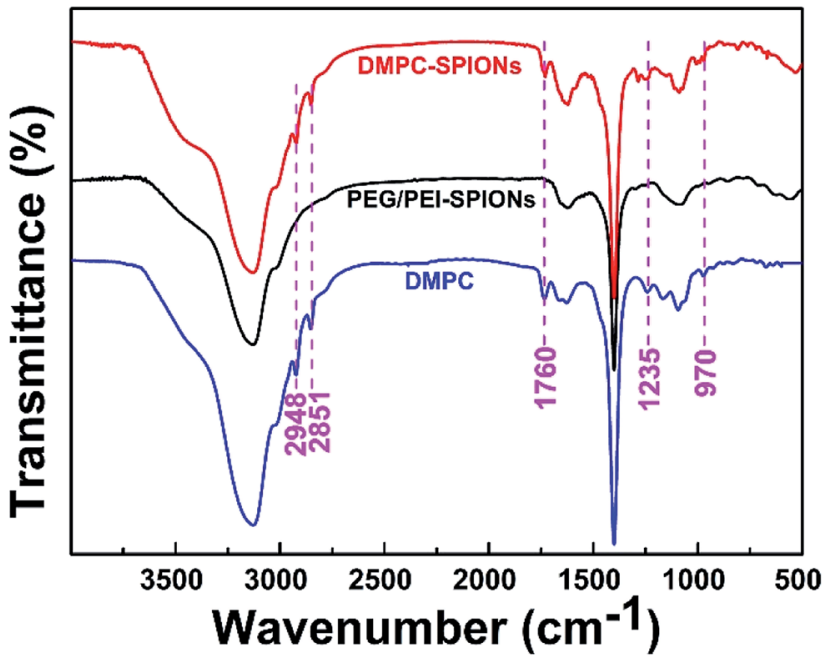

Fig. 3 FTIR spectra of DMPC-SPIONs and PEG/PEI-SPIONs. spectra of DMPC-SPIONs (Fig. 4d) can be curve fitted into three peaks by multiple Gaussians with an equal full width at halfmaximum (FWHM) using a Shirley-type background, and the binding energies at about 400, 401.34, and $403 \mathrm{eV}$ are attributable to the $\mathrm{N}-\mathrm{H}, \mathrm{C}-\mathrm{N}-\mathrm{C}$, and $\mathrm{N}^{+}-\left(\mathrm{CH}_{3}\right)_{3}$ groups of DMPCSPIONs. ${ }^{25,26}$ Both of the results of FTIR and XPS reveal that DMPC is modified on the surface of the SPIONs. After deduction of the weight losses under $120^{\circ} \mathrm{C}$ since these weight losses are due to the vaporization of water adsorbed into the DMPCSPIONs and PEG/PEI-SPIONs, it can be calculated from the thermogravimetric analyses (Fig. 5a) that about $31.7 \mathrm{wt} \%$ of DMPC was coated on the SPIONs. These nanoparticles show excellent superparamagnetic properties (Fig. 5b).

\subsection{In vitro cytotoxicity of PEG/PEI-SPIONs and DMPC- SPIONs}

Fig. 6 presents in vitro cytotoxicity of PEG/PEI-SPIONs and DMPC-SPIONs against PC-12 cells by MTT assay. It shows that the cell viabilities remain over $95 \%$ at different concentrations within $24 \mathrm{~h}$ for PEG/PEI-SPIONs and DMPC-SPIONs. These results indicate the low cytotoxicity of the PEG/PEI-SPIONs and DMPC-SPIONs.

\subsection{Subcellular distribution of the nanoparticles in PC-12 cells}

TEM results of the PC-12 cells incubated with the DMPCSPIONs show that nanoparticles entered the cells, densely packed in organelles (Fig. 7a-e), small fraction of the nanoparticles stayed on the cell membranes around the cilia (red hollow arrows in Fig. 7a and c). In order to determine that the black clusters are iron oxide nanoparticles rather than other impurities or dyes, EDS (Energy Dispersive Spectrometer) via TEM 2100F was employed to identify the black clusters. The electron beam was directed to electronically dense black clusters to collect a representative X-ray spectrum showing the Fe $\mathrm{K} \alpha$ peak (Fig. 8a and b). The peaks of copper $\mathrm{K} \alpha$, osmium $\mathrm{K} \alpha$ and uranium $\mathrm{K} \alpha$ were derived from the copper grid and chemicals for immobilization and staining of the cells. The result has confirmed the iron oxide composition. The lysosomes were filled with the nanoparticles (Fig. 7a). The internalized nanoparticles trafficking to lysosomes were often reported. ${ }^{27,28}$ It was also observed that the nanoparticles were accumulated around 

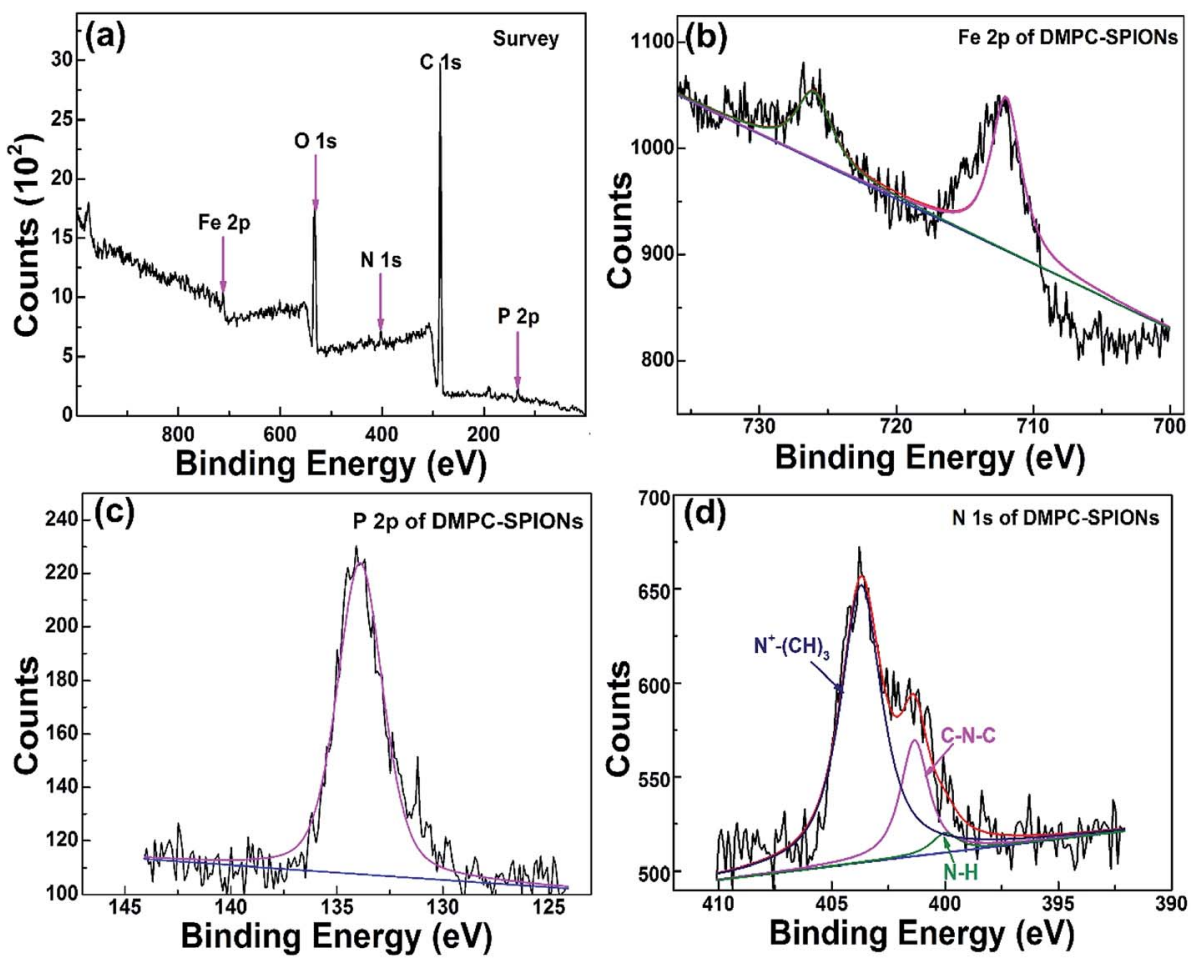

Fig. 4 XPS spectra: survey (a), Fe $2 p$ (b), P $2 p$ (c) and N 1s (d) of the DMPC-SPIONs.
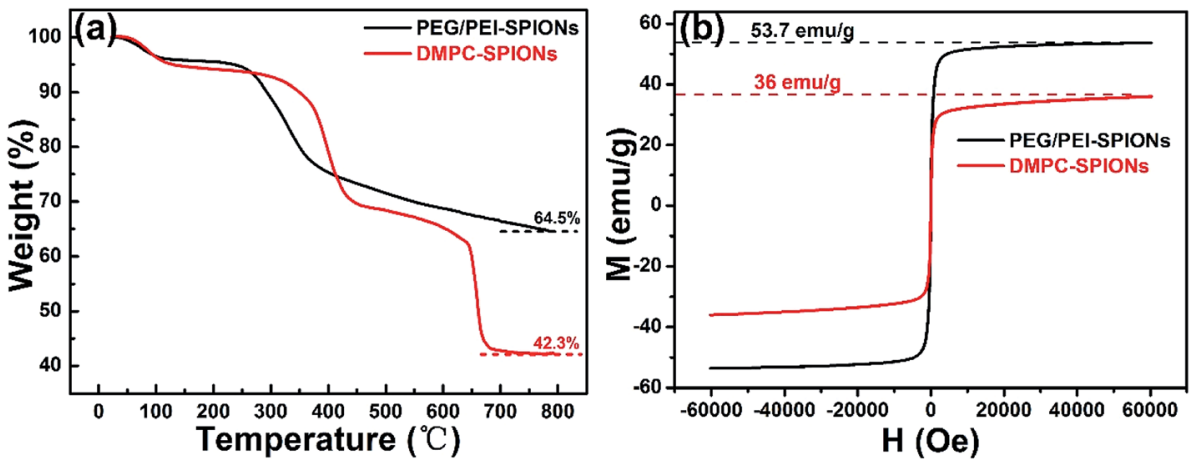

Fig. 5 TGA curves from 25 to $800^{\circ} \mathrm{C}$ of PEG/PEI-SPIONs and DMPC-SPIONs (a) and their hysteresis loops at $300 \mathrm{~K}$ (b).

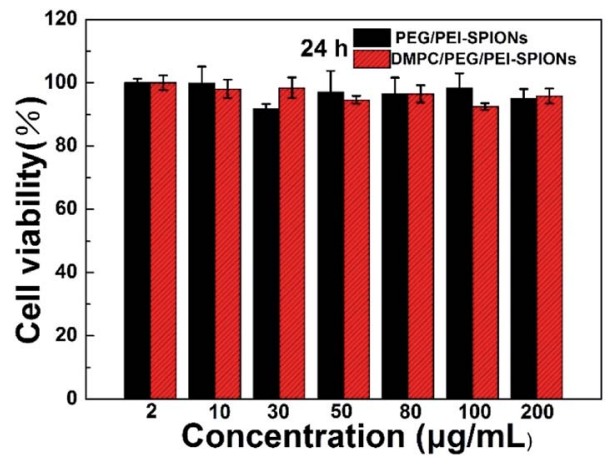

Fig. 6 Cell viabilities of PC-12 cells after incubation with PEG/PEISPIONs or DMPC-SPIONs at various concentrations for $24 \mathrm{~h}$. the nucleus (Nuc) (Fig. 7b) and in the endoplasmic reticulum (Fig. 7c and d). Fig. 7b and d reveal the well dispersed nanoparticles around the nucleus and in the endoplasmic reticulum with the same sizes as those of the synthesized DMPC-SPIONs (Fig. 1a). Iron oxide nanoparticles modified with dimercaptosuccinate near the nucleus in cultured astrocytes ${ }^{27}$ or iron oxide modified with glial fibrillary acidic protein located in the endoplasmic reticulum in cultured neuroglia of mouse ${ }^{29}$ were also reported. We also found that nanoparticles localized in the vesicles and in the mitochondrion (Fig. 7e), iron oxide nanoparticles modified with oligodeoxynucleotides could be accumulated by the vesicles in $\mathrm{N} 9$ cells as reported..$^{30}$ By comparison, less iron oxide particles were found in the PC-12 cells incubated with PEG/PEI-SPIONs and few iron oxide nanoparticles were found on the cell membrane (Fig. 7f). It can be seen from the 

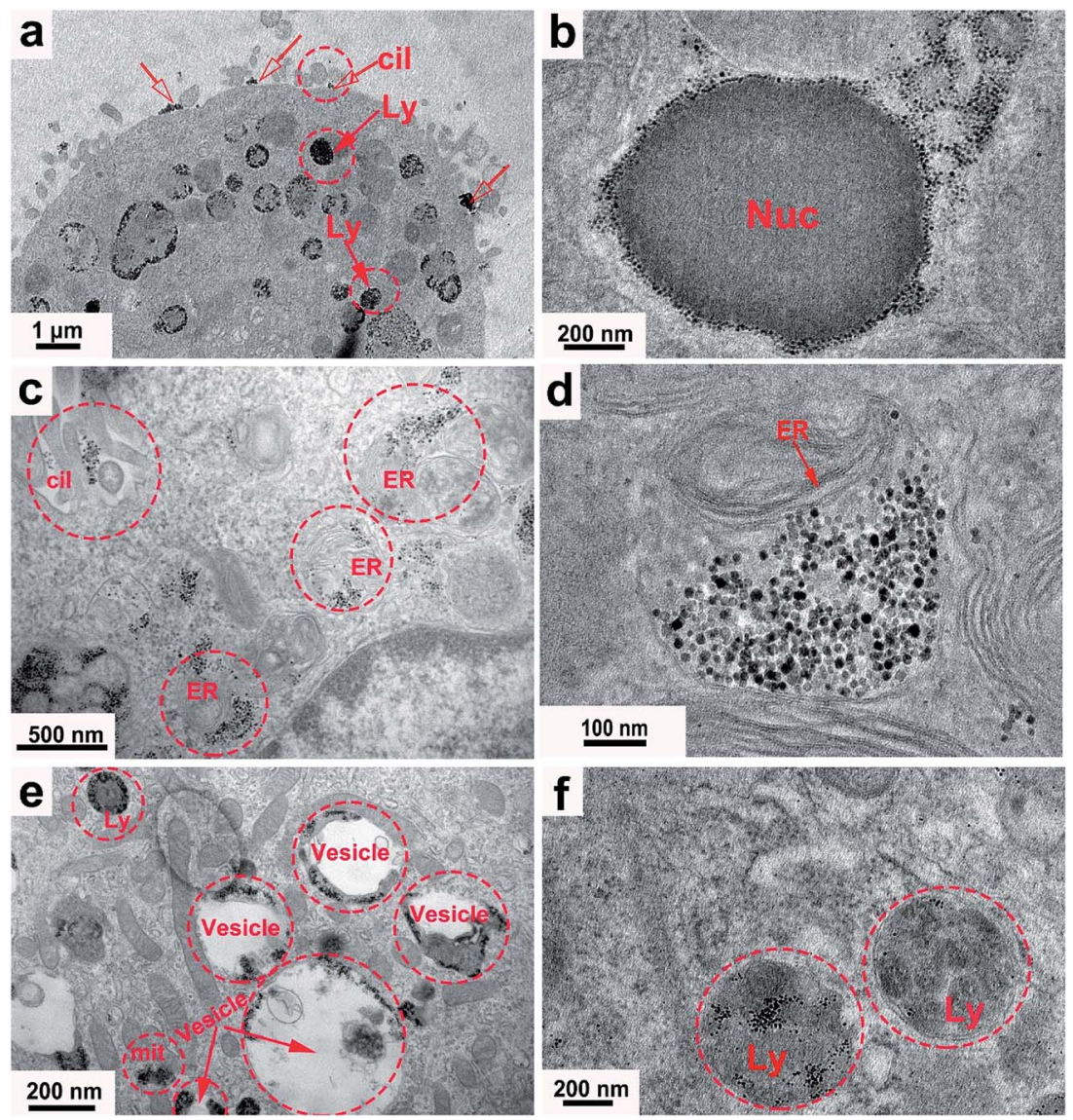

Fig. 7 Subcellular distribution of the DMPC-SPIONs (a-e), PEG/PEI-SPIONs (f) (Ly: lysosome, ER: endoplasmic reticulum, Nuc: nucleus, mit: mitochondrion, cil: cilia), (a), (b), (d) and (f) were observed by JEM-2100F operated at $200 \mathrm{kV}$; (c) and (e) were observed by H-7650 operated at $80 \mathrm{kV}$.

ICP-OES results (Fig. 9) that remarkably more iron content was present in PC-12 cells incubated with DMPC-SPIONs than in PC12 cells incubated with PEG/PEI-SPIONs. Our work shows the crucial role of DMPC in enhancing the endocytotic uptake of SPIONs. This may be attributed to the similarity between the chemical structures of DMPC and membrane phospholipids which result in the fusion of DMPC and cell membranes (Scheme 1). And it seems that the function of DMPC was not compromised even in the cells as DMPC-SPIONs were tending to fuse with the membranes in cells and the nanoparticles were accumulated by cellular organelles. This work encourages further researches related to DMPC-SPIONs being used as high efficient agents for cancer treatment by hyperthermia in external magnetic field, ${ }^{31}$ drug delivery, ${ }^{32}$ transfection, ${ }^{33}$ and magnetic resonance imaging (MRI) of cells. ${ }^{34}$ Cell imaging and tracking is important for the applications such as stem cell therapy. MRI tracking of stem cells requires labeling of the cells with enough contrast agents which allow them to be distinguished from the background. DMPC-SPIONs with high magnetic properties and their enhanced cellular uptake can be
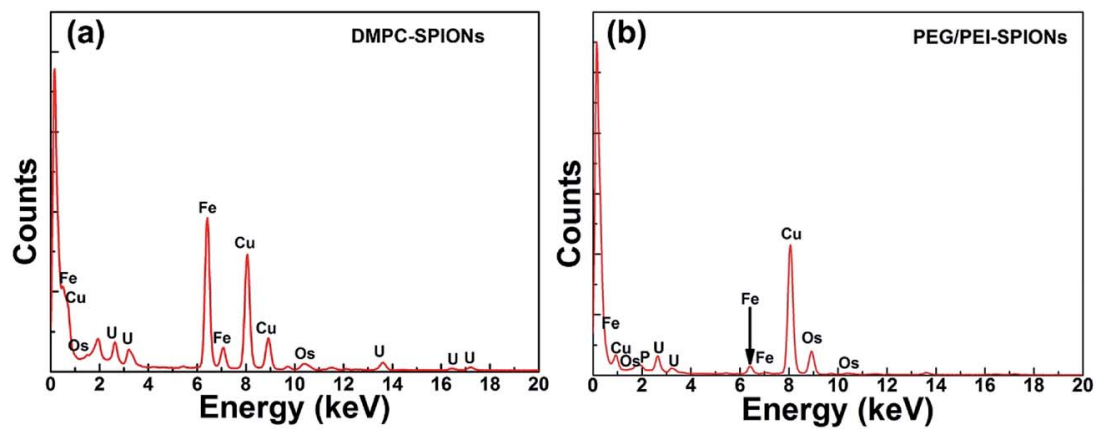

Fig. 8 EDS analysis of electron-dense black clusters in cells incubated with DMPC-SPIONs (a) or PEG/PEI-SPIONs (b) showing the presence of $\mathrm{Fe}$. 


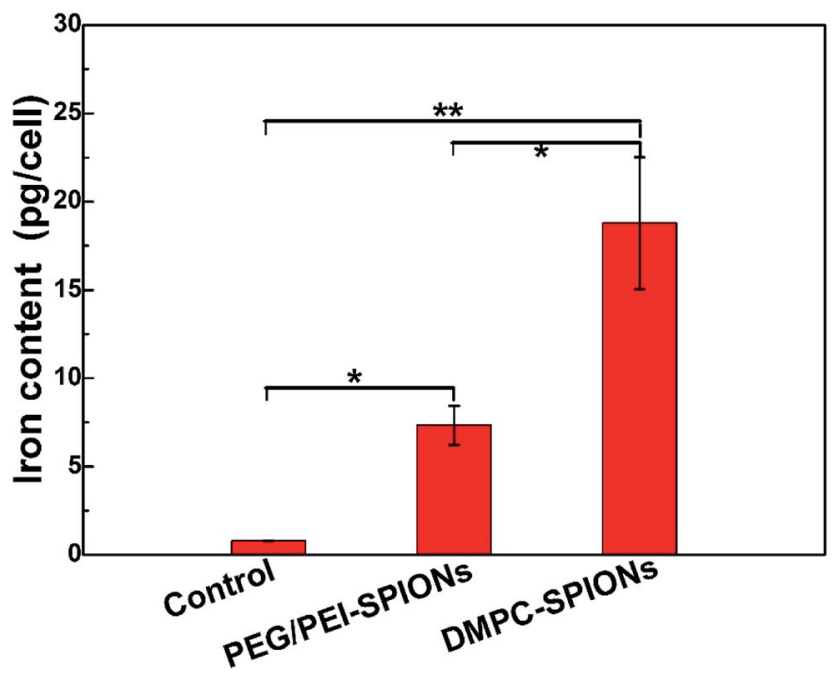

Fig. 9 ICP-OES analysis of the iron contents of the PC-12 cells incubated with PEG/PEI-SPIONs or DMPC-SPIONs. Statistical significance was evaluated using one-way ANOVA followed by post-hoc comparison of the means using the Fisher's least significant difference test, $n=3$. * represents $P<0.05$, ** represents $P<0.001$.

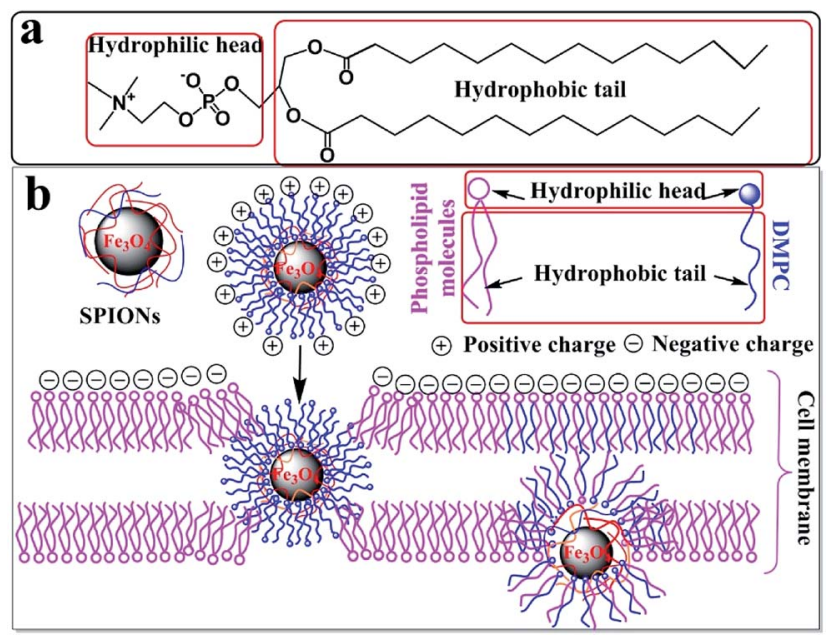

Scheme 1 The schema for DMPC, DMPC-SPIONs and their interaction with the cell membranes.

used as T2 contrast agents ${ }^{35}$ for MRI cell tracking. The enhanced cellular uptake of DMPC-SPIONs can increase the intracellular delivery of drugs or transfection agents that DMPC-SPIONs have carried, and may also result in the heating of the concentrated SPIONs in cancer cells under alternating or radio frequency magnetic fields so as to implement efficient hyperthermia therapy.

\section{Conclusions}

DMPC had been easily modified on the PEG/PEI-SPIONs. DMPC greatly enhanced the endocytotic uptake of DMPC-SPIONs. Densely accumulated nanoparticles were found in the lysosome, endoplasmic reticulum, mitochondrion, vesicle, and around the nucleus, some nanoparticles remained on the cell membrane. DMPC-SPIONs have potential in MRI imaging of cells and developing multifunctional platforms for cancer treatment by hyperthermia, drug delivery and transfection.

\section{Conflict of interest}

The authors declare no competing financial interests.

\section{Acknowledgements}

This work was financially supported by the National Natural Science Foundation of China (No. 51562007).

\section{References}

1 M. Mahmoudi, J. Meng, X. Xue, X. J. Liang, M. Rahman, C. Pfeiffer, R. Hartmann, P. R. Gil, B. Pelaz and W. J. Parak, Biotechnol. Adv., 2014, 32, 679-692.

2 A. Verma and F. Stellacci, Small, 2010, 6, 12-21.

3 A. Ozdemir, M. S. Ekiz, A. Dilli, M. O. Guler and A. B. Tekinay, RSC Adv., 2016, 6, 45135-45146.

4 M. Galli, A. Guerrini, S. Cauteruccio, P. Thakare, D. Dova, F. Orsini, P. Arosio, C. Carrara, C. Sangregorio, A. Lascialfari, D. Maggioni and E. Licandro, $R S C A d v$, 2017, 7, 15500-15512.

5 M. Ibáñez, R. Zamani, W. Li, A. Shavel, J. Arbiol, J. R. Morante and A. Cabot, Cryst. Growth Des., 2015, 12, 1085-1090.

6 M. B. Cortie and A. M. Mcdonagh, Chem. Rev., 2011, 111, 3713-3735.

7 A. Lassenberger, A. Scheberl, A. Stadlbauer, A. Stiglbauer, T. Helbich and E. Reimhult, ACS Appl. Mater. Interfaces, 2017, 9, 3343-3353.

8 S. Hong, A. U. Bielinska, A. Mecke, B. Keszler, J. L. Beals, X. Shi, L. Balogh, B. G. Orr and M. M. B. Holl, Interaction of Poly(amidoamine) Dendrimers with Supported Lipid Bilayers and Cells: Hole Formation and the Relation to Transport, Cambridge University Press, 2004.

9 M. Feng, Q. Cai, H. Huang and P. Zhou, Eur. J. Pharm. Biopharm., 2008, 68, 688-693.

10 S. K. Shukla, S. K. K. Shukla, P. P. Govender and N. G. Giri, RSC Adv., 2016, 6, 94235-94251.

11 P. Ai, H. Wang, K. Liu, T. Wang, W. Gu, L. Ye and C. Yan, RSC Adv., 2017, 7, 19954-19959.

12 K. Yan, P. Li, H. Zhu, Y. Zhou, J. Ding, J. Shen, Z. Li, Z. Xu and P. Chu, RSC Adv., 2013, 3, 10598-10618.

13 D. Ling, N. Lee and T. Hyeon, Acc. Chem. Res., 2015, 48, 12761285.

14 S. L. Jeon, M. K. Chae, E. J. Jang and C. Lee, Chem.-Eur. J., 2013, 19, 4217-4222.

15 H. Ba, J. Rodríguezfernández, F. D. Stefani and J. Feldmann, Nano Lett., 2010, 10, 3006-3012.

16 C. R. Miller, B. Bondurant, S. D. Mclean, K. A. Mcgovern and D. F. O'Brien, Biochemistry, 1998, 37, 12875-12883.

17 M. J. Murcia, D. E. Minner, G. M. Mustata, K. Ritchie and C. A. Naumann, J. Am. Chem. Soc., 2008, 130, 15054-15062. 
18 B. L. Zhang, Z. J. Tu, F. Y. Zhao and J. Wang, Appl. Surf. Sci., 2013, 266, 375-379.

19 F. Y. Zhao, B. L. Zhang, J. Wang and Z. J. Tu, J. Nanosci. Nanotechnol., 2013, 13, 6793-6797.

20 C. Jiang, A. Alla Gamarnik and C. P. Tripp, J. Phys. Chem. B, 2005, 109, 4539-4544.

21 J. Giri, S. G. Thakurta, J. Bellare, A. K. Nigam and D. Bahadur, J. Magn. Magn. Mater., 2005, 293, 62-68.

22 L. Minati, V. Micheli, B. Rossi, C. Migliaresi, L. Dalbosco, G. Bao, S. Hou and G. Speranza, Appl. Surf. Sci., 2011, 257, 10863-10868.

23 C. Yam, L. Zheng, M. Salmain, C. Pradier, P. Marcus and G. Jaouen, Colloids Surf., B, 2001, 21, 317-327.

24 P. H. Lo, W. T. Tsai, J. T. Lee and M. P. Hung, Surf. Coat. Technol., 1994, 67, 27-34.

25 J. R. Oliveira, M. C. L. Martins, L. Mafra and P. Gomes, Carbohydr. Polym., 2012, 87, 240-249.

26 K. R. Gopidas and P. V. Kamat, Langmuir, 1989, 5, 22-26.

27 C. Petters, K. Thiel and R. Dringen, Nanotoxicology, 2016, 10, 332-342.
28 E. M. Luther, C. Petters, F. Bulcke, A. Kaltz, K. Thiel, U. Bickmeyer and R. Dringen, Acta Biomater., 2013, 9, 8454-8465.

29 C. H. Liu, J. Yang, J. Q. Ren, C. M. Liu, Z. You and P. K. Liu, FASEB J., 2013, 27, 712-724.

30 E. E. White, A. Pai, Y. Weng, A. K. Suresh, H. D. Van, T. Pailevanian, D. Alizadeh, A. Hajimiri, B. Badie and J. M. Berlin, Nanoscale, 2015, 7, 7780-7789.

31 Z. Nemati, J. Alonso, H. Khurshid, M. H. Phan and H. Srikanth, RSC Adv., 2016, 6, 38697-38702.

32 J. Li, J. Mao, J. Tang, G. Li, F. Fang, Y. Tang and J. Ding, RSC Adv., 2017, 7, 22954-22963.

33 B. Neuhaus, B. Tosun, O. Rotan, A. Frede, A. M. Westendorf and M. Epple, RSC Adv., 2016, 6, 18102-18112.

34 G. Yang, W. Q. Ma, B. L. Zhang and Q. Xie, Mater. Sci. Eng., C, 2016, 62, 384-390.

35 J. Wang, B. L. Zhang, L. Wang, M. Wang and F. B. Gao, Mater. Sci. Eng., C, 2015, 48, 416-423. 